\title{
LA UNIDAD EN LA INTERPRETACIÓN JURISDICCIONAL DE LOS DERECHOS FUNDAMENTALES: UNA TAREA PENDIENTE EN EL DERECHO CHILENO*
}

\begin{abstract}
ANDRÉS BORDALí SALAMANCA**
RESUMEN: En materia de interpretación constitucional no existen mecanismos en el Derecho chileno que permitan garantizar la unidad jurisdiccional. El problema se presenta debido a que tanto la judicatura constitucional como la ordinaria aplican e interpretan la Constitución produciendo dispersión jurisprudencial. En el presente trabajo el autor propone instrumentos y prácticas que podrían acrecentar la unidad jurisdiccional en materia de interpretación de la Constitución y de los derechos fundamentales.
\end{abstract}

Palabras clave: Derechos fundamentales, seguridad jurídica, recurso de casación, amparo constitucional, Corte Suprema, derecho viviente, Derecho Procesal Constitucional, recursos procesales, Jurisdicción constitucional, casación constitucional.

ABSTRACT: Chilean legal system lacks procedures for unifying the judicial interpretations of the Constitution. The problem arises because both the Constitutional Court and the ordinary courts apply the Constitution not always in the same sense. This paper suggests different ways to reach some unity in judicial decisions about constitutional norms and fundamental rights.

Key words: Fundamental rights, legal certainty, cassation, "amparo constitucional", Supreme Court, living law, Constitutional Procedural Law, legal remedies, Constitutional jurisdiction, Constitutional cassation.

\section{INTRODUCCIÓN}

La certeza y predecibilidad del Derecho fueron unos de los postulados más importantes del movimiento ilustrado y luego codificador. Frente a un sistema jurídico atomizado propio del Estado jurisdiccional del medioevo, el moderno Estado de Derecho reclamaba una mayor racionalidad del sistema jurídico y un mayor respeto de la igualdad de los ciudadanos. Para ello era indispensable simplificar el sistema jurídico, unificándolo y facilitando su conocimiento. Desde el punto de vista de las fuentes normativas el binomio ley (estatal)-código fue la herramienta diseñada para tales fines.

\footnotetext{
* Este trabajo ha sido realizado en el marco y con el financiamiento del proyecto Fondecyt no 1050388 , "Certeza e igualdad en la tutela jurisdiccional de los derechos fundamentales" del cual el autor de este trabajo es su investigador responsable. Agradezco la colaboración en la presente investigación de los coinvestigadores Daniela Accatino Scagliotti y Juan Carlos Ferrada Bórquez.

** Abogado, Doctor en Derecho, Profesor de Derecho Procesal y Constitucional, Director del Instituto de Derecho Público y de la Revista de Derecho de la Universidad Austral de Chile, Casilla 567, Valdivia, correo electrónico: abordali@uach.cl, teléfono 63-293364, fax 63-293194.
} 
Desde el punto de vista de la aplicación judicial del Derecho solo un orden de tribunales ordinarios debía aplicar la ley y para la unidad jurisprudencial se creó el recurso de casación.

Sin embargo, la historia nos demuestra que los valores de certeza y predecibilidad del Derecho en muchos ordenamientos jurídicos, como el chileno, no han podido nunca ser realizados en plenitud. La Corte Suprema chilena raras veces ha respetado sus decisiones previas. La casación no ha podido unificar la interpretación judicial de la ley.

A nivel general esta situación empeoró radicalmente con el Estado Constitucional de Derecho que surge luego de la Segunda Guerra Mundial. Desde este momento se entiende que la Constitución debe ser aplicada por todos los tribunales de justicia como cualquier otra norma jurídica. Ese empeoramiento se debe a que jamás se diseñaron instrumentos procesales para unificar las interpretaciones dadas por los distintos tribunales a la Constitución Política de la República.

Inicialmente Kelsen no previó mayormente este problema puesto que su Tribunal Constitucional prospectado en la Constitución austriaca de 1920 tenía el monopolio en la aplicación de la norma constitucional y, además, como se sabe, la función de ese tribunal se limitaba, mediante un control de tipo abstracto, a expulsar del ordenamiento jurídico una ley contraria a la Constitución. No había por tanto necesidad de unificar criterio jurisprudencial alguno en materia constitucional.

Los problemas surgen cuando los tribunales constitucionales comienzan a realizar interpretaciones de la ley a modo de hacerla compatible con el texto constitucional. Se trata de las conocidas sentencias interpretativas de los tribunales constitucionales que compiten con la función de nomofilaxis encargada a las cortes de casación. Del mismo modo, los tribunales ordinarios se sienten vinculados directamente a la Constitución y comienzan a interpretarla y aplicarla compitiendo así con los tribunales constitucionales.

En el caso de Chile esta situación se agudiza especialmente después del golpe de Estado de 1973, donde a los tribunales ordinarios (1976) se les encarga la tutela directa de los derechos fundamentales a través del Recurso de Protección. Luego se construye doctrinal y judicialmente la Nulidad de Derecho Público (1980 en adelante). Más adelante se crean otras figuras para la tutela de los derechos fundamentales, como es el caso por ejemplo del Amparo Económico. Últimamente el legislador ha encomendado a la Corte Suprema la tutela del derecho fundamental a un debido proceso a través del recurso de nulidad que regula el Código Procesal Penal (art. 373 a CPP). A todo ello se puede agregar el hecho que un sector de la doctrina entiende que todo tribunal de justicia debe dar aplicación directa de la Constitución en virtud del mandato del artículo 6º de la Constitución Política de 1980 (en adelante CPR).

Vemos de este modo que la simplificación del Derecho que era uno de los postulados del movimiento ilustrado y codificador, se ve obstaculizada en el Estado Constitucional de Derecho que supone considerar a la Constitución como norma jurídica. La situación se hace más compleja debido a que aumentan por un parte las fuentes normativas (se agrega la Constitución con su particular naturaleza de norma de principios por sobre la ley) y, de otra, los tribunales de justicia que deben aplicar esas normas (se agregan las cortes constitucionales), pero no se crean instrumentos procesales que permi- 
tan unificar las decisiones que sobre el conjunto de estas normas dan el conjunto de los tribunales de justicia involucrados.

Quizá España es uno de los pocos países que ha creado un instrumento que ha sido capaz en ciertos casos de unificar la jurisprudencia constitucional. Eso es así al menos en materia de derechos fundamentales. Es el caso del Amparo Constitucional español que ha conseguido unificar la jurisprudencia sobre los derechos fundamentales, aunque con el altísimo costo de atascar la actividad del Tribunal Constitucional español afectando gravemente su funcionamiento.

En las páginas que siguen quiero analizar si es posible intentar unificar las decisiones de los tribunales de justicia en materia de interpretación de la Constitución, con especial referencia a los derechos fundamentales. Para tales efectos abordaré (I) cómo se han presentado en la experiencia comparada (Italia, España y Francia) y en Chile los roces y fricciones entre tribunales constitucionales y tribunales supremos como máximos tribunales de la judicatura ordinaria. En seguida (II) discutiré quién debe ser el máximo defensor de la Constitución, donde analizaré desde una perspectiva histórica el funcionamiento del recurso de casación como instrumento para la defensa de la norma jurídica y la unidad jurisprudencial. En este mismo numeral consideraré la posibilidad de realizar la función de nomofilaxis con respecto a la norma constitucional y si es posible que el Tribunal Constitucional desarrolle tal labor, para terminar con un estudio de cómo deberían ser las relaciones entre el Tribunal Constitucional y la Corte Suprema chilena en la defensa de la Constitución y los derechos fundamentales. Finalmente (III), formularé unas conclusiones generales.

\section{ROCES Y FRICCIONES ENTRE TRIBUNALES CONSTITUCIONALES Y TRIBUNALES SUPREMOS}

\section{Por las agitadas aguas del Mediterráneo. Conflictos en Roma y en MADRID}

En trabajos anteriores ${ }^{1}$ he estudiado la génesis de los conflictos entre judicatura constitucional y judicatura ordinaria. Esos conflictos han estado representados a veces por duros enfrentamientos entre cortes constitucionales y tribunales supremos. La situación más conocida, especialmente por la virulencia que alcanzó, fue la que se dio entre la Corte Constitucional y la Corte de Casación italianas. En Madrid también se han dado situaciones similares.

La causa de estos conflictos entre cortes no tiene su origen principal, como podría creerse en el hecho que la Constitución Política de la República sea concebida como una norma jurídica directamente aplicable por todos los tribunales de justicia, sean constitucionales o de la judicatura ordinaria. En Italia la causa de los referidos conflictos entre cortes se debió a que la Corte Constitucional comenzó a disputar con la Corte de Casación la interpretación de la ley. El mecanismo utilizado para tal labor han sido las

${ }^{1}$ Bordalí (2005b) pp. 96-103; Bordalí (2006) pp. 40-45. 
denominadas sentencias interpretativas, como explico en los trabajos citados precedentemente $^{2}$. En este sentido, ha sido la Corte Constitucional italiana la que ha invadido el campo soberano de la Corte de Casación, cual es la interpretación definitiva de la ley.

En el caso de España los conflictos entre cortes se han dado también por esta invasión por parte del Tribunal Constitucional de los dominios del Tribunal Supremo a través de las sentencias interpretativas. Pero las pugnas no solo tienen esa causa, sino también por la posibilidad que tiene el Tribunal Constitucional de anular sentencias del Tribunal Supremo vía Amparo Constitucional ${ }^{3}$. En este último caso, los conflictos se han dado porque en muchos casos el Tribunal Constitucional cuando acoge un amparo no se limita a dar tutela a un derecho o libertad vulnerada, sino que con bastante frecuencia enjuicia la forma como los tribunales de la judicatura ordinaria, incluido el Tribunal Supremo, interpretan y aplican las leyes, siendo que tales tareas son encomendadas expresamente por la Constitución y las leyes a esos tribunales ordinarios ${ }^{4}$.

$\mathrm{Ni}$ en Italia ni en España se han creado instrumentos procesales que permitan solucionar los conflictos ocasionados por las sentencias con contenidos divergentes dictadas por los dos órdenes jurisdiccionales. En Italia, desde la década de los ochenta del siglo pasado, se ha producido una cierta tranquilidad a través de lo que se denomina el "diálogo entre las cortes" 5 . España no ha generado ninguna práctica similar.

Las sentencias interpretativas se dan en el ámbito de la Justicia Constitucional represiva y han implicado un drástico redimensionamiento de la función nomofiláctica de las cortes supremas, en cuanto se les sustrae en todo o en parte la tarea de individualizar cuál norma se deba extraer de la disposición examinada ${ }^{6}$.

Las sentencias interpretativas intentan evitar los problemas que se podrían presentar con ocasión de la anulación de una ley. Sin embargo, en países como Francia que no tienen un control represivo de constitucionalidad de la ley, sino solo preventivo, también han surgido este tipo de sentencias interpretativas que pretenden vincular a la judicatura ordinaria. Lo mismo ha sucedido en Chile. Veremos a continuación cómo se relacionan las cortes constitucionales y la judicatura ordinaria en Francia y en nuestro país.

\section{ARÍS ESQUIVA PARCIALMENTE LA TORMENTA}

En Francia, las relaciones entre judicatura constitucional y ordinaria han comenzado a generarse por un proceso de ocupación del terreno constitucional por parte de todos los jueces de la República. Estas relaciones se tornaron algo más delicadas desde que el Conseil Constitutionnel expande su ocupación del territorio constitucional. En efecto, desde la decisión del Conseil Constitutionnel de fecha 16 de julio de 1971 sobre la libertad de asociación, por la que se "constitucionaliza" la declaración de Derechos del año 1789 y el Preámbulo de la Constitución de 1946, ha existido una mayor disputa

\footnotetext{
${ }^{2}$ Véase también este tema en BORDALí (2005a) pp. 249-252.

3 CARMONA (2005) p. 92.

4 PÉrez Gordo (1983) pp. 131-141.

5 Para un análisis de esta situación remito a BORDALí (2006) pp. 42-45.

${ }^{6}$ Silvestri (2001) p. 41.
} 
sobre la soberanía constitucional. Esta disputa se ha dado especialmente con la jurisdicción administrativa, toda vez que antes que la jurisdicción constitucional, el Conseil d'Etat ya había determinado que tanto la Declaración de Derechos como el Preámbulo de la Constitución eran algo más que textos programáticos. En este sentido, se ha dicho que en Francia el "ocupante originario" del territorio constitucional ha sido históricamente el juez administrativo y no el constitucional. El juez administrativo desde antaño ha interpretado la Constitución a propósito del control de legalidad de los actos administrativos a través del recurso por exceso de poder ${ }^{7}$.

Pero el Conseil d'Etat ha ampliado su ocupación del territorio constitucional por otra vías, a la que también se ha sumado la Corte de Casación, quienes impulsados por el propio Conseil Constitutionnel se han declarado competentes para juzgar la conventionalité de las leyes, es decir, la conformidad o no de estas con los textos europeos sobre derechos fundamentales. Algo semejante ha ocurrido con la tutela de urgencia que la ley de 30 de junio de 2000 entregó a los jueces administrativos, a través del référé administratif para la tutela de las libertades fundamentales ${ }^{8}$.

En general las relaciones generadas por esta múltiple ocupación del territorio constitucional han sido pacíficas. Ha existido una situación similar a la italiana de "diálogo entre cortes". Solo en ciertos casos aislados el Conseil d'Etat ha asumido una posición más aguerrida, no resignándose a ceder respecto a su título soberano de originario ocupante del territorio constitucional. En la mayoría de los casos el Conseil d'Etat interpreta la Constitución de conformidad con los criterios predefinidos por el Conseil Constitutionnel?.

Asimismo, las relaciones con la Corte de Casación han sido en general de diálogo más que de confrontación. Como algo excepcional, la doctrina ${ }^{10}$ pone como un ejemplo aislado de insubordinación de la Corte de Casación el caso Breisacher del año 2001, donde la Corte hizo notar su autonomía en la interpretación constitucional en el marco del caso relativo al estatuto penal del Presidente de la República. La Corte de Casación interpretó de una manera autónoma el artículo 68 de la Constitución, apartándose de la decisión adoptada previamente por el Conseil Constitutionnel con fecha 22 de enero de 1998 sobre el tratado sobre la Corte Penal Internacional.

La doctrina francesa constata esa situación de diálogo pero además exalta sus virtudes. Así Dominique Rousseau ${ }^{11}$ destaca que un enunciado normativo se construye a través de una relación compleja entre todos aquellos que hacen uso de él. En este sentido, la Justicia Constitucional es uno más de los actores de este juego, del que participan también el Parlamento y, habría que agregar, las demás jurisdicciones. A su juicio, los jueces constitucionales no son la garantía última o trascendente de una verdad absoluta y definitiva del sentido producido, sino que se limitan a garantizar que la producción de sentido de un enunciado constitucional haya respetado un procedimiento

\footnotetext{
7 BURGORGUE-LARSEN (2004) pp. 48-57.

${ }^{8}$ Burgorgue-Larsen (2004) pp. 60-61.

${ }^{9}$ Burgorgue-Larsen (2004) p. 50; Drago (2006) p. 636.

10 Drago (2006) p. 644.

11 Rousseau (2004) pp. 15-16.
} 
de deliberación entre actores múltiples. El funcionamiento del Conseil Constitutionnel se construye sobre un puente obligatorio de diálogo para que se genere un acuerdo sobre el sentido normativo deseado.

Sin perjuicio de esta convivencia más o menos pacífica entre cortes en la interpretación constitucional, respecto de las sentencias interpretativas que dicta el Conseil Constitutionnel la situación no ha sido igualmente pacífica. Es decir, como en Italia, la principal disputa entre cortes ha sido producto de la interpretación de la ley y no de la Constitución.

Hay que mencionar que el Conseil Constitutionnel ha ejercitado intensivamente la práctica de las sentencias interpretativas. $\mathrm{Y}$ es su doctrina que las interpretaciones que realiza de la ley vinculan a las autoridades que tienen por función aplicar la ley, es decir, a las autoridades administrativas y jurisdiccionales ${ }^{12}$. Esta doctrina tiene como antecedente el artículo 62 de la Constitución francesa que dispone que "las decisiones del Consejo Constitucional se imponen a las autoridades administrativas y jurisdiccionales". Veremos que un sector importante de la doctrina no está de acuerdo con esta conclusión o al menos no la comparte en plenitud.

Antes de analizar las situaciones de fricción generadas entre cortes francesas producto de las denominadas sentencias interpretativas, es curioso constatar que estas sentencias se den en el sistema jurídico francés. Es que una de las principales razones para utilizar las sentencias interpretativas es impedir el mayor daño que se podría presentar producto de la anulación de una ley que está rigiendo. Suponen además un control de tipo represivo por vía incidental ${ }^{13}$. Pues nada de ello existe en Francia donde como se sabe el control es de tipo preventivo y abstracto.

A juicio de Drago ${ }^{14}$ la utilización de estas sentencias interpretativas se debe a una posición cómoda del Conseil Constitutionnel, que le permite evitar una censura al legislador, pero que afecta la claridad de la decisión y genera efectos inciertos respecto de los otros tribunales y autoridades administrativas. En cierto sentido, mediante ellas el Conseil descarga la responsabilidad constitucional en otras autoridades.

La duda que se ha planteado en Francia sobre la vinculación de estas sentencias interpretativas respecto de los jueces administrativos y de la judicatura ordinaria radica en determinar si solo la parte resolutiva de la sentencia es la que vincula a los demás jueces, o si también la parte expositiva. Se trata de determinar si la autoridad de estas sentencias corresponde solo a la cosa juzgada o si también existe una autoridad de "cosa interpretada", posición esta última que ha sustentado muchas veces el propio Conseil Constitutionnel ${ }^{15}$.

Ahora bien, desde un punto de vista jurídico formal, un sector de la doctrina francesa destaca que no existe ningún instrumento que asegure que las autoridades administrativas y jurisdiccionales apliquen las reservas de interpretación que ha efectua-

\footnotetext{
12 www.conseil-constitutionnel.fr/langues/espagnol/compete.htm

13 Bordalí (2005a) pp. 249-252.

${ }^{14}$ Drago (2006) p. 536.

15 Drago (2006) pp. 551-552.
} 
do el Conseil Constitutionnel. Efectivamente el artículo 62.2 de la Constitución francesa no prevé ningún mecanismo formal que permita al Conseil verificar y sancionar la aplicación de sus decisiones.

A juicio de Viala ${ }^{16}$ ni siquiera se podría hablar de efecto de cosa juzgada respecto de las decisiones del Conseil Constitutionnel. Entonces, las reservas de interpretación ven su aplicabilidad completamente librada a la discreción y gracia de los órdenes jurisdiccionales. Y en la práctica, los jueces ordinarios, de un modo general, han acatado de un modo fiel y estricto las reservas de interpretación formuladas por el Conseil.

Como se puede observar, las relaciones entre cortes francesas no han sido especialmente conflictivas. Sin embargo, han generado una dispersión jurisprudencial que no ha contribuido precisamente a la claridad y certeza del ordenamiento jurídico francés.

\section{Calma momentánea en CHile}

La diversidad de decisiones entre órdenes jurisdiccionales es aún más compleja en el Derecho chileno si le la compara con la situación europea descrita precedentemente. Es que no solo hay diversidad de pareceres sobre la interpretación de la ley por medio de las sentencias interpretativas que utiliza el Tribunal Constitucional ${ }^{17}$, sino que hay una clara competencia entre dichos órdenes jurisdiccionales a propósito de la interpretación de la Constitución y los derechos fundamentales. Dicha diversidad de pareceres es especialmente evidente a propósito del control represivo de la constitucionalidad de la potestad reglamentaria del Presidente de la República que puede realizar el Tribunal Constitucional, la que simultánea o en otro momento también puede ser impugnada a través del Recurso de Protección y por medio de la Nulidad de Derecho Público. Un caso paradigmático de esta situación que expongo se presentó con ocasión de la impugnación del Decreto Supremo no 143 que cancelaba la personalidad jurídica de la Sociedad Benefactora y Educacional Dignidad ${ }^{18}$.

En otro orden de cosas, la Corte Suprema está facultada para tutelar el derecho fundamental a un debido proceso penal por medio del recuso de nulidad procesal penal (art. 373 a) CPP ${ }^{19}$. Mediante esa competencia la Corte Suprema podría interpretar el referido derecho fundamental, rivalizando con interpretaciones que previa o posteriormente haya realizado el Tribunal Constitucional.

Podría agregarse una ulterior dificultad. Ella se presentaría si la Corte Suprema procediera a considerar que el recurso de casación en el fondo es procedente no solo por infracción de ley, sino también por infracción de la norma constitucional, como sugiere un sector de nuestra doctrina constitucional ${ }^{20}$. Y todo ello sin perjuicio de que cada

\footnotetext{
16 Viala (1999) pp. 251-256.

${ }^{17}$ A modo ejemplar, puede consultarse la técnica de las sentencias interpretativas utilizadas por el Tribunal Constitucional en el fallo recaído sobre el proyecto de ley que crea juzgados laborales y de cobranza laboral y previsional, rol no 442 (2005).

${ }^{18}$ Sobre el problema surgido en este caso remito a BORDALÍ (2005b) pp. 100-101.

19 Para un estudio de la jurisprudencia de la Corte Suprema en relación al artículo 373a) CPP remito a LÓPEZ (2006) pp. 199-207.

${ }^{20}$ FERNÁNDEZ (2005) pp. 110-118.
} 
Tribunal de la República puede considerarse inmediata y directamente vinculado a la Constitución en virtud de una interpretación en tal sentido del artículo $6^{\circ} \mathrm{CPR}$.

A todo ello se debe agregar que es muy probable que la competencia entre el Tribunal Constitucional y la Corte Suprema por la interpretación definitiva de la ley aumente, debido a que uno de los presupuestos para la utilización de las sentencias interpretativas es evitar anular por inconstitucionalidad las leyes, competencia anulatoria que como sabemos tiene reconocida hoy en día el Tribunal Constitucional (art. 93 no 7 CPR).

En este escenario descrito, hay que señalar que en nuestro país no hay instrumento procesal ni práctica alguna que permita coordinar eventuales decisiones contradictorias en materia de interpretación de la Constitución y de la ley dadas por el Tribunal Constitucional y por la judicatura ordinaria. Todo ello conspira claramente contra los valores de certeza y predecibilidad del Derecho, afectándose asimismo el derecho de los ciudadanos a la igualdad ante la Constitución y la ley.

En las páginas que siguen analizaré si es posible en nuestro ordenamiento jurídico tender hacia una mayor unidad en la interpretación de la Constitución, especialmente en materia de derechos fundamentales.

\section{I. ¿QUIÉN DEBE SER EL MÁXIMO DEFENSOR DE LA CONSTITUCIÓN Y LOS DERECHOS FUNDAMENTALES?}

\section{LA DEFENSA DE LA UNIDAD JURISPRUDENCIAL A TRAVÉS DEL RECURSO DE CASACIÓN}

\section{a) Consideraciones previas}

El orden jurídico que nace luego de la Revolución Francesa intentó velar fuertemente por la seguridad jurídica, el principio de igualdad ante la ley y la unidad del Derecho. Para ello se hizo preciso someter la aplicación del Derecho a reglas que lo hicieran uniforme en el tiempo y el espacio, de modo tal que la decisión judicial resultara predecible e igual en todos los casos y en todo el territorio. El instrumento que se crea para cumplir tales fines es el recurso de casación.

El "moderno" 21 recurso de casación nace en Francia en el año 1837 con el fin de obtener la defensa de la ley o nomofilaxis, o como se ha entendido, para obtener una

\footnotetext{
${ }^{21}$ En Francia el instrumento de la casación se conoce desde el año 1578 con el denominado Conseil des parties que era un órgano político y no jurisdiccional cuyo fin era tutelar las prerrogativas del rey frente a los tribunales de justicia, con especial consideración de los parlaments. Se comportaba dicho órgano como una corte de casación puesto que estaba facultada para anular las decisiones de los tribunales que violaban las ordenanzas del monarca. Desde luego que los miembros del Consejo carecían de independencia e inamovilidad. Estaban claramente sometidos al poder regio. Y por ello es que eran considerados funcionarios políticos antes que judiciales. Luego de la Revolución, en 1790, se crea el Tribunal de Cassation. Este órgano adscrito al Poder Legislativo y no al Judicial era en lo esencial una especie de corte constitucional que tenía por fin controlar jurídicamente la recta observancia de aquellas normas constitucionales que regulaban las relaciones y límites entre el poder judicial y el legislativo. El tribunal podía anular las decisiones de los tribunales de justicia que violaran las leyes dadas por el parlamento.
} 
correcta o exacta interpretación de la ley. Con el tiempo se agregó también la función de ser garantía de la uniformidad de la jurisprudencia.

España instituyó un sistema diverso de casación. En primer lugar, la función de nomofilaxis es más compleja que en Francia. En efecto, en la Ley de Enjuiciamiento Civil de 1855, el recurso de casación se extiende a las sentencias que infrinjan la "doctrina legal”, esto es, aquella señalada por el propio Tribunal Supremo en la interpretación de la ley. Luego, en el año 1984, se reemplaza el concepto de "doctrina legal" por el de jurisprudencia. Persigue por tanto la casación española "establecer un criterio uniforme en la aplicación e interpretación de la ley"22.

Pero hay otra característica de la casación española que lo diferencia radicalmente de un modelo puro de casación. Esa variación hispana, como veremos, llegó a nuestro medio jurídico. El recurso de casación español no se limita con atribuir competencia al Tribunal Supremo para anular una sentencia contra ley o contra su propia jurisprudencia, sino que extiende ese poder para la dictación de una segunda sentencia, cual es la que reemplaza a la anulada.

La casación (en el fondo) chilena, siguiendo el modelo español, permite a la Corte Suprema, luego de invalidar la sentencia recurrida, dictar la sentencia de reemplazo sobre la cuestión materia del juicio que haya sido objeto del recurso de casación, según lo que crea conforme a la ley y al mérito de los hechos tales como se han dado por establecidos en el fallo recurrido (art. 785 CPC).

Este modelo de casación rompe con la configuración original del recurso en Francia, que se caracteriza por atribuir a una corte de justicia una función cercana a la legislativa. Al permitírsele dictar a los tribunales de casación, como sucede en España y en Chile, además de la sentencia anulatoria, aquella que reemplaza a la impugnada, quiere ello decir que ese órgano se comporta como un tradicional tribunal de justicia, solucionando el caso en sus propios términos. Se aleja de este modo el modelo hispano de casación de esa particular función cuasi legislativa con la cual fue configurado el mecanismo en Francia.

En el caso chileno, el modelo de casación sufre un serio problema de identidad, debido a que fue diseñado sobre la base de un tipo estricto o puro de casación, es decir, con el sentido con el que nació en Francia en el siglo XIX, pero que por diversos factores, como decisiones legislativas y la propia práctica de la Corte, ha derivado en una especie de tercera instancia ${ }^{23}$.

La conversión de las Cortes Supremas en tribunales de la instancia antes que órganos que cumplen esencialmente una función colaboradora de la actividad legislativa no solo se ha dado en países como Chile y España, sino que parece ser la tónica en muchos países de tradición continental ${ }^{24}$.

Veremos a continuación cómo puede ser compatible esta concepción "jurisdiccional" de las cortes supremas con la función de contribuir a la uniformidad en la interpretación jurisdiccional.

22 De OTTO (2001) p. 294.

23 ATRIA (2005) p. 275.

${ }^{24}$ Silvestri (2001) p. 39. 


\section{b) Casación y uniformidad en la interpretación judicial de la ley}

Aminorada hoy en día la sospecha que tenían los revolucionarios franceses de actividad subversiva de los jueces, quienes con sus sentencias podían imponer su criterio particular a la voluntad popular expresada democráticamente en la ley, trae ello como consecuencia que la función esencial de la casación no puede quedar centrada exclusivamente en un mecanismo de control de los jueces. De este modo, el fin de asegurar la uniformidad en la interpretación judicial de la ley se ha convertido hoy en día en el más importante de la casación.

La nomofilaxis entendida como exacta interpretación de la ley no tiene sentido hoy en día si no se la vincula con la idea de uniformidad de la jurisprudencia. ¿Qué significa que la Corte Suprema mediante el recurso de casación pueda determinar la exacta interpretación de la ley que debe aplicarse a un caso concreto? Considerado el asunto en un caso individual, no pasa de ser un juego abstracto de conceptos que lo único que justifica es que la Corte Suprema se convierta en una tercera instancia jurisdiccional revisora de lo fallado por las Cortes de Apelación. Se trataría así de un recurso jurisdiccional más al haber de los justiciables que retrasa la respuesta judicial que quizá años antes podría haber dado una Corte de Apelación ${ }^{25}$.

Si ha de tener sentido determinar la exacta interpretación de la ley, es porque permitirá generar mayor certeza y seguridad jurídicas. De no ser así solo se alarga innecesariamente la respuesta jurisdiccional. Se trata de que la Corte Suprema pueda formular una regla de juicio universalizable que pueda ser utilizada en el futuro por el conjunto de los tribunales de justicia que deben aplicar e interpretar la ley en casos similares. Para Taruffo ${ }^{26}$ esto equivale a decir que el indicador para medir la adecuación de la interpretación de una norma en sede de decisión no es tanto la adecuación de aquella interpretación para resolver el conflicto de intereses específico que caracteriza el caso particular, sino la capacidad de aquella interpretación para servir como criterio de decisión para soluciones sucesivas de casos idénticos o similares ${ }^{27}$. Ese es el sentido de entender a la Corte Suprema como corte de "justicia" que es respetuosa del derecho de los ciudadanos a la igualdad ante la ley. Es la igualdad de los ciudadanos antes la ley antes que la unidad del ordenamiento jurídico el fin más importante que resalta un sector de la doctrina respecto del recurso de casación ${ }^{28}$.

El fin de la uniformidad en la interpretación de la ley es también propio de la casación en el fondo chilena, al menos desde la reforma practicada al instituto con la ley

\footnotetext{
25 Como lo expresa Mario Morelli, en Italia, el recurso de casación, de medio excepcional puesto para una tutela objetiva de la coherencia del ordenamiento jurídico, ha terminado por el contrario por convertirse en el instrumento cuya difusión y subrepticia utilización ha implicado duplicar (cuando no triplicar o cuadriplicar) los tiempos fisiológicos del proceso. MORELLI (2001) p. 82.

26 TARUFFO (2001) p. 97

27 Elisabetta Silvestri ha señalado que la tarea de una corte de casación no es la verificación de la legalidad de la decisión realizada en el caso individual, sino otra más comprometida, que consiste en interpretar la ley como regla general dirigida a disciplinar "clases" de supuestos fácticos normativos. SiLVESTRI (2001) p 109.

28 Silvestri (2001) p. 45; Romero Seguel (2004) p. 115.
} 
no 19.374 de 1995. En efecto, dicha ley modificó el artículo 780 CPC en el sentido apuntado, de modo tal que la Corte Suprema cuenta hoy en día con los medios idóneos para producir mayor uniformidad en la interpretación de la ley, dotando de este modo a las decisiones judiciales de una mayor predecibilidad. El artículo 780 CPC le permite a la Corte cumplir su misión de fijar reglas uniformes para la decisión de casos análogos ${ }^{29}$.

Es evidente que el precedente que contribuye a consolidar la Corte Suprema no puede tener una naturaleza formalmente vinculante ${ }^{30}$. Nuestro ordenamiento jurídico no autoriza a la Corte Suprema para crear normas jurídicas paralelamente al Congreso Nacional o al Presidente de la República. Formalmente la Constitución Política de la República de 1980 no lo prevé; por otra parte, mientras esa Corte carezca de legitimidad democrática no es bueno que pueda hacerlo. El precedente que configura la Corte Suprema tendrá una vinculación en la medida que goce de autoritas, pero no obliga a los demás tribunales como si fuese una norma jurídica más. Para ello se debería avanzar en la dirección que se ha dado en España, donde desde la Ley de Enjuiciamiento Civil de 1855 se ha configurado el recurso de casación respecto de sentencias que infrinjan la "doctrina legal" o "jurisprudencia” del Tribunal Supremo ${ }^{31}$.

El sentido que tiene el peculiar recurso de casación español no es claro en su dogmática ni en su sistema de fuentes del Derecho. Así, para De Otto ${ }^{32}$, es claro que si una sentencia judicial puede ser anulada al infringir la jurisprudencia del Tribunal Supremo, es porque esa sentencia es tan antijurídica como aquella que es contraria a la ley. Y todo ello quiere decir que los jueces tienen el deber de sentenciar conforme a la jurisprudencia, pues negar tal deber y afirmar que el juez es libre de sentenciar conforme o contra esta sería tanto como mantener la tesis absurda de que el juez pueda optar entre sentencias con arreglo a Derecho o hacerlo en términos antijurídicos.

El Tribunal Constitucional español no ha seguido igual criterio puesto que considera que no existe una sola vía para interpretar la ley, lo que deriva en que no puede existir una sola jurisprudencia válida. La tolerancia del referido tribunal frente a la diversidad jurisprudencial es hoy bastante amplia. Esa tolerancia deriva de la especial consideración hacia la independencia judicial y de la consideración del Poder Judicial como un poder difuso. Asume de este modo que la potestad jurisdiccional no conoce jerarquías. No hay en este sentido tribunales inferiores ni superiores. La vinculación que tiene el juez es hacia la norma legal. Lo único que exige hoy en día el Tribunal Constitucional español es que las distintas interpretaciones que han dado los jueces sean razonables y justificadas. "De esta manera, para el Tribunal Constitucional la jurisprudencia se configura sobre todo como el resultado del funcionamiento de un Poder Judicial forma-

\footnotetext{
29 Romero SEGUel (2004) p. 114.

${ }^{30}$ Para un estudio del precedente en el Derecho chileno remito a ACCATINO (2002) pp. 559 y ss.

31 El fin de unificar la doctrina del Tribunal supremo español ha estado siempre presente en el Derecho español. Aparte de las disposiciones contenidas en la legislación procesal civil (hoy fundamentalmente art. $4772 n^{\circ} 3^{\circ}$ LEC / 2000), también en el orden procesal administrativo y laboral existen mecanismos para unificar los criterios interpretativos de la ley. En sede laboral, por ejemplo, existe el recurso de casación para la unificación de la doctrina. RODRÍGUEZ-PIÑERO (1999) pp. 45 y ss.; IVORRA (1997) pp. 13 y ss.

32 De Отто (2001) p. 299.
} 
do por jueces independientes y sometidos en exclusiva al imperio de la ley; como una realidad dinámica y en continua evolución, en la que conviven distintas interpretaciones de la norma, todas válidas desde una perspectiva constitucional, y cuya elección corresponde al juez en ejercicio de su jurisdicción sin más limitación que la interdicción de la arbitrariedad en su actuación" 33 .

Vemos de este modo que la propia función jurisdiccional parece ser la que conspira contra los intentos de unificar la interpretación de la ley, impidiendo dar mayor certeza y predecibilidad al Derecho. Parece ser esencial a la jurisdicción el particularismo frente a la generalidad y vinculación formal que caracteriza a la función legislativa.

Y si cierta inseguridad jurídica parece ser inevitable con respecto a la interpretación judicial de la ley, ella puede acrecentarse aún más cuando los tribunales de justicia no solo deben aplicar las leyes sino también la Constitución. Existe una corriente doctrinaria que sostiene que los jueces deben dar aplicación directa de la Constitución. Fallar según Derecho equivaldría a fallar de conformidad con todo el conjunto de normas jurídicas, comenzando por la Constitución. A quien le correspondería velar por la correcta interpretación de la Constitución en el caso en concreto es a la Corte Suprema vía recurso de casación. Examinaremos a continuación si ello es posible y qué problemas presenta desde el punto de vista del valor de la seguridad jurídica.

\section{LA NORMA CONSTITUCIONAL Y EL RECURSO DE CASACIÓN}

Convengamos en que no existe en el ordenamiento jurídico chileno ninguna norma que establezca que el monopolio de la interpretación constitucional pertenece al Tribunal Constitucional. Y desde luego no lo puede haber si se parte de la base que las leyes chilenas atribuyen la aplicación judicial de la Constitución tanto al Tribunal Constitucional (art. 93 CPR) como a los tribunales ordinarios (artículos 20 y 21 CPR; artículo único Ley 18.971, etcétera). Pero un sector de la doctrina expande mucho más esa posibilidad de los tribunales de justicia de aplicar -y por lo tanto de interpretar- la Constitución en virtud del artículo $6^{\circ} \mathrm{CPR}$. En este sentido ha señalado últimamente Miguel Ángel Fernández que los preceptos constitucionales "no requieren mediación normativa alguna para aplicarse a los hechos o situaciones concretas regidas por ellos, a menos que el propio Poder Constituyente haya impuesto, con el rasgo de deber, la necesidad de dicha mediación"34. La principal consecuencia de este planteamiento radica en el hecho que los tribunales de justicia, tanto ordinarios o especiales, deberán considerar tanto la normativa ordinaria como la constitucional al fallar lo asuntos sometidos a su conocimiento y decisión. De este modo, para Fernández ${ }^{35}$, tanto la Constitución como la ley en sentido estricto constituyen el término ley para efectos del recurso de casación. La Corte Suprema, vía recurso de casación, aparece como el órgano que debe "verificar y orientar el significado de las disposiciones constitucionales para su aplicación por los jueces del fondo en todas las causas en que

\footnotetext{
33 RodrígueZ-PiÑero (1999) p. 287.

${ }^{34}$ FERNÁNDEZ (2005) p. 102.

35 FERNÁNDEZ (2005) p. 110.
} 
deban acudir a las mismas disposiciones para la resolución del asunto que les corresponde conocer" 36 .

La idea de que la Corte Suprema pueda controlar la interpretación constitucional vía recurso de casación en el fondo ha sido constantemente rechazada por la misma Corte. Y esa posición es correcta. Hay que distinguir diversos aspectos en este punto. Efectivamente, se puede considerar que todos los tribunales de justicia, tanto ordinarios como especiales, están directamente vinculados a la Constitución. Esto quiere decir que es válido que los jueces interpreten la normativa infraconstitucional de conformidad con los preceptos constitucionales. Inclusive, a mi juicio, esos jueces estaban facultados en el pasado para ir más allá en el caso que no pudieran acomodar la interpretación de la ley a la Constitución, pudiendo inaplicar en el caso concreto un precepto legal cuya aplicación en esa situación consideraran contraria a la Constitución. Con la reforma a la Constitución mediante la Ley 20.050 de 2005 ello ya no es válido porque se ha concentrado esa facultad de inaplicación en el Tribunal Constitucional (art. 93 no 6 CPR).

En mi concepto las sanciones que determina el ordenamiento jurídico respecto a la vulneración del orden jurídico deben ser interpretadas estrictamente. En este sentido solo el Tribunal Constitucional podría inaplicar o anular una ley. Asimismo, solo la Corte Suprema puede anular una sentencia judicial por atentar contra el texto de una ley. Esto último se hace mediante el recurso de casación en el fondo. Y por ley se debe entender legislación en sentido estricto, no la Constitución.

¿Qué razones existen para sostener esta posición restrictiva del recurso de casación en el fondo? En primer lugar razones de texto. El artículo 767 CPC se refiere específicamente a infracción de ley. Cuando el legislador ha querido ampliar el ámbito de la nulidad de las sentencias judiciales por atentar contra normas jurídicas se ha referido expresamente como infracción de Derecho y no de ley, como sucede actualmente con el recurso de nulidad procesal penal (art. 373 b) CPP).

Pero aun cuando se dijese infracción de Derecho en vez de ley tampoco necesariamente se debe concluir que ello incluye a la norma constitucional. Es que se pierde todo el sentido histórico de la casación considerando a la norma constitucional como objeto del recurso de casación. La casación es parte del sistema de defensa del orden democrático. Se trata que la voluntad del pueblo no sea alterada por la decisión particular de un juez. Pero para que el sistema pueda funcionar esa voluntad del pueblo debe estar expresamente detallada por una norma jurídica de modo que el órgano de casación pueda controlar si se respeta o no esa voluntad. Deben tener por tanto esas normas jurídicas una densidad regulativa tal que permita cumplir la función.

Es cierto que la ley no siempre tiene la densidad normativa suficiente, o bien no siempre es clara, de modo tal que los jueces no se limitan a aplicarla sino que terminan creando al menos en parte la norma. Y eso mismo ocurre con el recurso de casación. Determinar el correcto sentido de la ley en sede de casación tiene un claro aspecto de

36 FERNÁNDEZ (2005) p. 110. 
creación de Derecho por parte de la Corte de Casación ${ }^{37}$. Pero la densidad normativa de la Constitución es infinitamente inferior a la de la ley, por lo que determinar el correcto sentido de la norma constitucional termina siendo un puro acto de deliberación política dada en este caso por un órgano (Corte Suprema) que carece de legitimidad democrática, sin que represente en lo más mínimo la voluntad del pueblo. De este modo, el respeto del principio democrático desaconseja entregar a los jueces de la Corte Suprema la correcta interpretación de la norma constitucional.

La diferencia esencial entre normas legales y constitucionales es visualizada por Fernando Atria ${ }^{38}$ en que las primeras pretenden adjudicar nuestros conflictos mientras que las normas constitucionales pretenden identificar los fundamentos de nuestra comunidad política. Se habla asimismo que los textos constitucionales contienen "conceptos esencialmente controvertidos" lo que dificulta la aplicación jurisdiccional de la Constitución en el marco de un Estado de Derecho que proscribe la arbitrariedad y que valora la seguridad jurídica ${ }^{39}$. Por ello se debe ser muy cuidadoso en la aplicación directa de la Constitución ya que la adjudicación del conflicto no será en muchos casos obra de la voluntad general sino del criterio particular de uno o más jueces.

Ahora bien, es cierto que en experiencias comparadas algunas cortes de casación han considerado a la Constitución como norma a tutelar mediante la función de nomofilaxis, pero ello se ha debido a fenómenos excepcionales de crisis o transición institucional. En Italia, desde que en el año 1948 entra en vigencia la Constitución de la Postguerra, la Corte de Casación operó como una corte constitucional, puesto que la referida Constitución consagraba una corte constitucional para que desarrollase tal actividad, pero esta no entró en funciones hasta el año 1956. De este modo, desde 1948 a 1955, todos los jueces italianos, así como la Corte de Casación como tribunal del vértice de la estructura, operaron en calidad de órganos responsables del control de constitucionalidad de las leyes ${ }^{40}$. Luego en 1956, cuando entra en funciones la Corte Constitucional, la doctrina entendió que la Corte de Casación continuaría conociendo en exclusiva de las cuestiones de legalidad ordinaria y no de constitucionalidad.

Las cortes de casación no deben considerar a la Constitución dentro de su función de nomofilaxis y uniformidad en la interpretación judicial. Ello no solo es inconveniente desde el punto de vista del respeto del Estado de Derecho, sino que aumenta los grados de inseguridad jurídica al entrar a competir con las cortes constitucionales como defensores de la Constitución y los derechos fundamentales.

Afortunadamente, como ya se ha indicado, la Corte Suprema chilena se ha negado reiteradamente a incluir a la norma constitucional en su función de corte de casación. Sin embargo, no ha podido escapar del cometido constitucional y legal de conocer de procesos judiciales de tutela de derechos fundamentales, lo que ha implicado que dicha Corte se convierta en un supremo intérprete de la Constitución, compitiendo de este

\footnotetext{
37 TARUFFO (1991) p. 88

38 ATRIA (2006) p. 15.

${ }^{39}$ Sobre este aspecto remito a ACCATINO (2006) pp. 17-18.

40 CAMPanelli (2005) p. 105.
} 
modo con el Tribunal Constitucional. ¿Qué hacer en esta situación para propender hacia una unificación de la interpretación jurisdiccional de la Constitución, con especial referencia a los derechos fundamentales? Una alternativa posible a explorar es hacer del Tribunal Constitucional una "supercorte de casación" con el poder de anular las sentencias de la Corte Suprema que vulneren su doctrina asentada en materia de derechos fundamentales. Se trata de explorar la posibilidad de crear una especie de recurso de casación para la unificación de la doctrina constitucional. Analizaremos críticamente esta posibilidad en el próximo apartado.

\section{EL TRIBUNAL CONSTITUCIONAL COMO TRIBUNAL DE CASACIÓN}

Así como precedentemente descartamos la idea de hacer de la Corte Suprema un tribunal de control de constitucionalidad de las leyes a través del recurso de casación, el objetivo ahora a analizar es si es factible hacer del Tribunal Constitucional chileno un tribunal de casación con el poder de anular las sentencias de la Corte Suprema que infrinjan la correcta interpretación de la Constitución. En particular, es mayormente probable concebir ese poder para anular aquellas sentencias que vulneren los derechos fundamentales reconocidos en el texto constitucional ya que es sobre esa materia donde la actividad de la Corte Suprema incide mayormente.

La idea de hacer del Tribunal Constitucional una especie de tribunal de casación no es peregrina. En efecto, un sector de la doctrina española considera que el Amparo Constitucional de derechos fundamentales, competencia del Tribunal Constitucional español, es en su esencia un recurso de casación. Es la tesis de Manuel Aragón ${ }^{41}$, la que Francisco Rubio Llorente ${ }^{42}$ rechaza toda vez que el Amparo Constitucional, a su juicio, no tiene como razón de ser fijar la doctrina del Tribunal Constitucional en materia de derechos fundamentales, aunque también sea instrumento para ello. La función principal del amparo, expresa este último autor, "es la protección de derechos, restableciendo en su ejercicio a aquel que se ha visto privado de él. Solo cuando ese restablecimiento se logra simplemente con la retroacción, será esta la medida a adoptar. Cuando no baste con ello porque se trata de derechos sustantivos o, aun tratándose de derechos procesales, se han producido sentencias contradictorias, la retroacción de las actuaciones, la devolución del asunto al juez ordinario, no es la medida adecuada para restablecer al amparado en su derecho, y es este restablecimiento el que el tribunal ha de asegurar" 43.

Sin embargo, la práctica del Tribunal Constitucional en materia de tutela de derechos fundamentales de contenido procesal parece indicar una lógica casacional, toda vez que en las sentencias estimatorias de amparo generalmente se procede a declarar la nulidad de la resolución judicial que provocó dicha vulneración, así como a retrotraer las actuaciones al órgano jurisdiccional ordinario competente para que dicte una nueva resolución, respetando esta vez las garantías de contenido procesal ${ }^{44}$.

\footnotetext{
41 ARAGÓN (2004) pp. 148 y ss.

42 Rubio Llorente (1995) p. 166.

43 Rubio Llorente (1995) p. 166.

44 Carmona (2005) p. 70.
} 
Constituya o no el Amparo Constitucional materialmente un recurso de casación por violación de los derechos fundamentales reconocidos en la Constitución, lo cierto es que se ve como una alternativa bastante plausible a los fines de unificar las decisiones jurisdiccionales en materia de derechos fundamentales. Sin embargo, como hemos puesto de manifiesto en trabajos anteriores ${ }^{45}$, la introducción del recurso de Amparo Constitucional en el orden jurídico español ha ocasionado un verdadero incordio, atascando la actividad del Tribunal Constitucional por años, lo que atenta contra una justicia que debe dar respuesta dentro de plazos razonables. Por otro lado, ha generado en más de una ocasión serios enfrentamientos entre el Tribunal Constitucional y el Tribunal Supremo, el que ha visto anuladas algunas de sus sentencias y criticado su actuar jurisdiccional por parte del primero. La relativa mayor seguridad jurídica que ha logrado obtener el sistema español de tutela jurisdiccional de derechos fundamentales se ha logrado a unos costos muy elevados, por lo que no creo que sea una alternativa a considerar en el Derecho chileno.

Si se ha de crear un recurso procesal en manos del Tribunal Constitucional chileno a fin de contribuir a la mayor unidad en la interpretación jurisdiccional de la Constitución y de los derechos fundamentales, creo que debe ser concebido en términos claramente casacionales puros, es decir, como tutela del ius constitutionis y no del ius litigatoris. Esto quiere decir que la solución al caso concreto en materia de tutela de derechos fundamentales deben darla los tribunales de la judicatura ordinaria. El Tribunal Constitucional no debería revisar esa actuación, salvo que afectara su doctrina o jurisprudencia en materia de derechos fundamentales. De este modo, ese recurso debería ser un recurso de casación para la unificación de la doctrina constitucional ${ }^{46}$.

Un recurso de este tipo no estaría predispuesto como mecanismo de control de la interpretación judicial o de defensa del ordenamiento, sino a los fines de evitar la dispersión jurisprudencial que puede producirse por la multiplicidad de tribunales que tutelan e interpretan los derechos fundamentales. El antecedente de un recurso semejante es el Derecho español. Podemos analizar críticamente cómo ha funcionado en dicho país en el orden procesal laboral para ver sin es posible proyectarlo al orden constitucional de nuestro país.

El recurso de casación para la unificación de doctrina en sede laboral ha sido considerado por un sector de la doctrina española como la casación por excelencia, el más casacional de todos los tipos de casación, que lo retrotrae al modelo originario perfilado luego de la Revolución Francesa. Este recurso se orienta directamente hacia la consecución de uno de los fines tradicionales de esta figura, cual es la unificación de doctrina ${ }^{47}$. El antecedente de este recurso que tiene por fin asegurar la unificación de doctrina es el recurso de casación en interés de ley de la Ley de Enjuiciamiento Civil

\footnotetext{
45 BORdAlí (2005b) pp. 109 y ss.; BORDALí (2006) pp. 59 y ss.

46 La doctrina francesa no descarta la creación de un sistema de "impugnaciones" de este tipo como única vía para hacer efectivamente vinculantes las interpretaciones de la Constitución dadas por el Conseil Constittionnel. DraGo (2006) p. 560.

47 Rodríguez-Piñero (1999) p. 65.
} 
española ${ }^{48}$, actualmente regulado en el Capítulo VI del Título IV (De los recursos) de la Ley de Enjuiciamiento Civil española de 2000.

El recurso de casación en interés de la ley del campo procesal civil ha sido considerado un fracaso por un sector de la doctrina, toda vez que su carácter público, su defensa del ius constitutionis, es tan extremadamente marcado que la sentencia de casación no tiene la capacidad de anular la sentencia impugnada, la que se mantiene plenamente vigente y aún ejecutable. La sentencia de casación solo tiene la capacidad de formar o acrecentar la jurisprudencia ${ }^{49}$.

Debido al fracaso del recurso de casación en interés de la ley, el actual recurso de casación para la unificación de doctrina del campo laboral fue concebido no solo como una respuesta frente a la dispersión jurisprudencial, sino que es capaz de producir efectos sobre la situación jurídica creada por la sentencia impugnada.

Se ha entendido que este recurso de casación busca tutelar dos derechos constitucionales existentes en el Derecho español, como lo son el de seguridad jurídica y la igualdad ante la ley. A fin de dar tutela a estos derechos, el Tribunal Supremo español aparece facultado para anular las sentencias de los tribunales inferiores que atentan contra esos derechos constitucionales ${ }^{50}$.

Se caracteriza esta casación por no realizar juicios sobre la calidad en la interpretación de una norma que hacen los tribunales inferiores, sino que, aunque pueda parecer en principio contrario a la naturaleza casacional, se pronuncia sobre una cuestión de hecho y no de Derecho, cual es la existencia de sentencias contradictorias, reponiendo la situación a la unidad jurisprudencial anterior.

La experiencia española sobre esta materia parece demostrar que el fin del recurso no ha servido para dar mayor unidad en la interpretación jurisdiccional de la ley. En primer lugar, el Tribunal Supremo no se ha entendido atado de manos respecto de las interpretaciones contradictorias que han dado los Tribunales Superiores de Justicia, y que por ser contradictorias puede anular. En efecto, el Tribunal Supremo en muchos casos ha entrado a establecer cuál es la interpretación correcta de la ley, por lo que el recurso ha pasado a desempeñar además del rol de unificador de doctrina, el de defensa de la correcta interpretación de la ley como conoce habitualmente en vía de casación ${ }^{51}$. En segundo lugar, se ha producido también un colapso de casaciones de este tipo, toda vez que los justiciables son legitimados activos para interponer el recurso. Esto ha hecho que los litigantes presenten estos recursos como última arma para la defensa de sus intereses, siendo que el legislador habría querido la consecución de un fin público y no privado, cual es la unidad jurisprudencial. Finalmente, y como ya se ha hecho notar, la virtualidad del recurso a los fines de la unidad jurisprudencial no ha sido avalada por la doctrina del Tribunal Constitucional español, el que ha considerado que la seguridad jurídica no puede conseguirse a costa de la independencia de cada uno de los tribunales del Poder Judicial ${ }^{52}$.

\footnotetext{
48 IVORRA (1997) p. 15.

49 IVORRA (1997) p. 17.

50 RodrígueZ-PiÑERo (1999) p. 67.

51 RodríguEZ-PIÑERO (1999) p. 136.

52 RodrígueZ-PIÑERO (1999) pp. 128 y ss.
} 
Valorando como antecedente esa experiencia española, un recurso de casación para la unificación de la doctrina constitucional en manos del Tribunal Constitucional chileno, para que pudiera contribuir adecuadamente en evitar la dispersión jurisprudencial en materia de derechos fundamentales, debería contemplar los siguientes aspectos:

A) En primer lugar, el Tribunal Constitucional no debería enjuiciar en general las interpretaciones que sobre derechos fundamentales ha realizado la Corte Suprema. Solo debe determinar si los fallos de la Corte Suprema contradicen su doctrina previamente establecida, procediendo por tanto el Tribunal Constitucional a anular el fallo impugnado y a dictar una nueva sentencia restableciendo la doctrina vulnerada.

B) En segundo lugar, a fin de evitar que el trabajo del Tribunal Constitucional colapse con miles de recursos de este tipo, es indispensable poner de manifiesto el fin público y no privado del recurso. Sin perjuicio que en el Derecho chileno pudiera entenderse que las sentencias contradictorias afectarían el derecho fundamental de los justiciables a la igualdad ante la ley, y por lo tanto resultaría coherente una legitimación activa ordinaria en cabeza de cada persona afectada por una respuesta jurisdiccional dispar, se debería poner énfasis en este caso en el rol público del recurso, cual instrumento para la realización del fin institucional de contribuir a la seguridad jurídica. En este sentido, parece apropiado legitimar activamente solo a entes públicos que representen ese fin público o institucional. Podría ser esta una de las tareas a desarrollar en el futuro por la Fiscalía Judicial.

C) En tercer lugar, el Tribunal Constitucional podría imponer a todos los tribunales sus interpretaciones en materia de derechos fundamentales, con la posibilidad manifiesta de anular las decisiones de la judicatura ordinaria que se aparten de su doctrina. Pero para aumentar aún más las competencias del Tribunal Constitucional se hace indispensable incrementar su legitimidad democrática. Es claro que el Tribunal Constitucional en esta materia, así como en muchas que la Constitución le encomienda (art. 93 $\mathrm{CPR}$ ), se comportaría más cercano a un órgano legislativo que a uno jurisdiccional. Es que en ningún caso resolvería situaciones concretas tutelando los intereses de los justiciables. Por el contrario, este recurso de casación contribuiría al proceso de creación de normas jurídicas vinculantes. Pero para ello el Tribunal Constitucional debe estar más cercano a la voluntad popular. Se requiere de este modo que sus integrantes solo puedan ser designados por órganos que tengan legitimidad democrática directa ${ }^{53}$, como lo son la Cámara de Diputados, el Senado y el Presidente de la República. En este sentido, no se ve apropiado encomendarle más competencias que inciden sobre el proceso de creación de normas jurídicas mientras algunos de los jueces constitucionales no sean designados por órganos representativos de la voluntad popular.

No tengo dudas de la virtualidad de un recurso de este tipo para contribuir a la unificación de la interpretación jurisdiccional en materia constitucional, con especial consideración de los derechos fundamentales. Y creo que ese fin se puede lograr sin que colapse la actividad de nuestro Tribunal Constitucional. Sin embargo, esta solución

\footnotetext{
53 Sin perjuicio de que se deba mejorar el nivel de representación popular del Congreso Nacional, realizan-
} do las reformas legales pertinentes. 
tiene un grave problema, cual es el de la irrealidad política, al alterar el equilibrio entre los poderes constitucionales y al necesitar para su consagración de una reforma constitucional (art. 93 CPR) que entregue esta competencia al Tribunal Constitucional.

Dada la improbabilidad de una nueva reforma constitucional en lo que respecta al Tribunal Constitucional, el que fue radicalmente modificado en la última reforma constitucional de agosto de 2005, parece más sensato hoy en día propender a una mayor seguridad jurídica en la interpretación jurisdiccional de la Constitución y de los derechos fundamentales si se apela directamente a los tribunales involucrados -Tribunal Constitucional y Corte Suprema- para que utilicen ciertas prácticas que no necesitan de reforma constitucional ni legal alguna. En este sentido, la experiencia italiana contemporánea de diálogo entre cortes puede ser muy útil, la que revisaré críticamente en el apartado que sigue.

\section{EL TRIBUNAL CONSTITUCIONAL Y LA CORTE SUPREMA COMO DEFENSORES DE LA CONSTITUCIÓN CHILENA. APRENDIENDO LAS LECCIONES DE UNA NUEVA PAX ROMANA}

Ya me he referido en otras ocasiones ${ }^{54}$ a la situación italiana, donde las cortes en estos últimos años han asumido una actitud colaboradora tanto en materia de interpretación constitucional como legal. En este mismo trabajo hemos constatado que una situación similar se da entre cortes en Francia.

Tomando como experiencia la evolución de la Justicia Constitucional italiana y francesa, se pueden articular de mejor manera las relaciones entre Tribunal Constitucional y Corte Suprema.

En primer lugar, atendido a que hoy en día el Tribunal Constitucional aparece facultado para anular leyes con efectos erga omnes (art. 93 no 7 CPR), es probable que aumenten las sentencias interpretativas, que lo que hacen es interferir incisivamente en la labor de la Corte Suprema como máximo intérprete de la ley. Para evitar futuros roces con la Corte Suprema es deseable que el Tribunal Constitucional se abstenga en lo posible de utilizar este tipo de sentencias. En ninguna parte el ordenamiento jurídico chileno autoriza este tipo de sentencias. Ahora bien, si el Tribunal Constitucional, en su concepto, se viera forzado por razones de interés institucional a utilizar este tipo de sentencias, es aconsejable que siga los criterios dados previamente por la Corte Suprema como corte de casación. Se trata de instituir la doctrina italiana del derecho viviente o vivo $^{55}$. El Tribunal Constitucional debe reconocer que en la exégesis de la norma ordinaria la primera palabra la tiene la Corte Suprema como tribunal de casación y no él ${ }^{56}$.

En segundo lugar, y en lo que a nosotros nos interesa mayormente en esta investigación, sería recomendable que en la exégesis de la norma constitucional la Corte Suprema viera en el Tribunal Constitucional al máximo defensor de la Constitución. La judicatura ordinaria, en los procesos de tutela de derechos fundamentales y de Nulidad

\footnotetext{
54 Remito a BORdalí (2006) pp. 42-45.

55 Bordalí (2006) p. 42.

${ }^{56}$ Morelli (2001) p. 84
} 
de Derecho Público, debería interpretar la Constitución según los parámetros que previamente haya establecido el Tribunal Constitucional, en la medida que estos existan. Por el contrario, el Tribunal Constitucional, por la especial posición que tiene como defensor de la Constitución en el sistema jurídico, no debería seguir aquellas interpretaciones del texto constitucional que a su juicio se alejen de una correcta interpretación constitucional. El tribunal Constitucional "debe siempre afirmar el favor constitutionis, aunque se aleje de una interpretación dada por la Corte de Casación” 57.

Que la interpretación que el Tribunal Constitucional hace de las normas constitucionales debe primar sobre el resto de la judicatura ordinaria es algo que se deriva de las propias competencias que la Constitución entrega a dicho tribunal (art. $93 \mathrm{CPR}$ ).

Y en este plano de colaboración entre cortes, la Corte Suprema chilena debería sentirse vinculada por las interpretaciones realizadas por el Tribunal Constitucional sobre la Constitución y los derechos fundamentales, ya sea por su eventual autoritas, pero muy especialmente partiendo de la especial posición del Tribunal Constitucional en el sistema jurídico chileno. Esto quiere decir que la Corte Suprema conociendo de las apelaciones de los recursos de protección, habeas corpus y amparo económico, así como en las casaciones en el fondo en las nulidades de Derecho público y en los recursos de nulidad procesal penal, debe atender a las interpretaciones que sobre la parte orgánica de la Constitución y, más frecuentemente, sobre los derechos fundamentales, haya dado el Tribunal Constitucional. En eso consistiría asumir la doctrina italiana del "derecho viviente" por la Corte Suprema chilena.

\section{CONCLUSIONES}

Pese a que las últimas reformas introducidas a la Constitución de 1980 han intentado concentrar la Justicia Constitucional chilena en manos del Tribunal Constitucional, en este como en otros trabajos he puesto de manifiesto que en materia de tutela e interpretación de los derechos fundamentales, esa competencia es difusa, pues se encuentra entregada tanto al Tribunal Constitucional como a la judicatura ordinaria.

En la experiencia chilena los dos órdenes jurisdiccionales han dado decisiones contradictorias en materia de derechos fundamentales y no hay instrumento alguno que permita coordinar esas decisiones. A los fines de una mayor certeza y seguridad jurídicas, lo más aconsejable parece ser la creación ante el Tribunal Constitucional de un recurso para la unificación de la doctrina constitucional, similar al que en el orden de la judicatura ordinaria existe en países como España. Sin embargo, ello supone modificar nuevamente la Constitución Política para entregarle esta nueva función al Tribunal Constitucional. En este sentido se trata de una propuesta que se aleja del realismo político.

Ponderando la realidad política nacional con una preocupación por mayor seguridad jurídica en materia de interpretación constitucional y de los derechos fundamentales, la experiencia comparada analizada -Francia e Italia- parece indicar que lo más razonable es invitar a un diálogo constante entre cortes. La doctrina del "derecho viviente" italiana parece ser el camino a seguir en adelante.

57 SiLVESTRI (2001) p. 42. 


\section{BIBLIOGRAFÍA CITADA}

ACCATINO, Daniela (2002): "El precedente judicial en la cultura jurídica chilena”, Anuario de Filosofía Jurídica y Social, Sobre la cultura jurídica chilena, Sociedad Chilena de Filosofía Jurídica y Social: pp. 559-582.

ACCATINO, Daniela (2006): "La interpretación de los derechos fundamentales y la seguridad jurídica. Una mirada a la práctica constitucional chilena”, BORDALÍ, Andrés (coord.), Justicia constitucional y derechos fundamentales (Santiago, Universidad Austral de Chile, LexisNexis) pp. 17-29.

Aragón, Manuel (2004): "Problemas del Recurso de Amparo", Pérez Tremps, Pablo (coord.), La reforma del Recurso de Amparo (Valencia, Universidad Carlos III de Madrid, Tirant lo Blanch) pp. 145-175.

ATRIA, Fernando (2005): "Proceso civil", Revista de Derecho de la Universidad Adolfo Ibáñez, Comentario de jurisprudencia del año 2004. Corte Suprema, Tribunal Constitucional y Tribunal Calificador de Elecciones, No 2: pp. 249-353.

ATRIA, Fernando (2006): "Seguridad jurídica y derechos fundamentales: Sobre predecibilidad y autogobierno”, BORDALÍ, Andrés (coord.), Justicia constitucional y derechos fundamentales (Santiago, Universidad Austral de Chile, LexisNexis) pp. 7-16.

BORDALÍ, Andrés (2005 a): "Análisis crítico del control preventivo y represivo de constitucionalidad de las normas jurídicas por los tribunales constitucionales", en: NOGUEIRA, Humberto (coord.), Jurisdicción constitucional en Chile y América Latina: Presente y prospectiva (Santiago, Universidad de Talca, LexisNexis) pp. 213-254.

BORDALí, Andrés (2005 b): "El modelo chileno de jurisdicción constitucional de las libertades. Análisis en el marco de los valores de seguridad jurídica e igualdad constitucional”, Revista de Derecho, Universidad Austral de Chile, vol. XVIII, No 1, julio: pp. 89 -117.

BORDALÍ, Andrés (2006): "La tutela de los derechos fundamentales bajo un sistema dual de justicia constitucional”, BORDALÍ, Andrés (coord.), Justicia constitucional y derechos fundamentales (Santiago, Universidad Austral de Chile, LexisNexis) pp. 33-65.

BURGORGUE-LARSEN, Laurence (2004): "La jurisprudence constitutionelle est-elle concurrencée par la jurisprudence constitutionnelle des jurisdictions ordinaires et européennes", Rousseau, Dominique (editor), Le Conseil Constitutionnel en questions (París, L'Harmattan) pp. 4575.

CAMPANElli, Giuseppe (2005): Incontri e scontri tra Corte suprema e Corte costituzionale in Italia e in Spagna (Turín, Giappichelli) 429 pp.

CARMONA, Encarna (2005): La crisis del recurso de amparo. La protección de los derechos fundamentales entre el Poder Judicial y el Tribunal Constitucional (Alcalá, Universidad de Alcalá, Servicio de Publicaciones), 141 pp.

De OTtO, Ignacio (2001): Derecho Constitucional. Sistema de fuentes (Barcelona, Ariel) 315 pp.

Drago, Guillaume (2006): Contentieux constitutionnel français (París, Thémes Droit Public) 759 pp.

FERnÁNDEZ, Miguel Ángel (2005): “Constitución y casación: ¿De la falta de aplicación al monopolio constitucional”, Estudios constitucionales, Revista del Centro de Estudios Constitucionales, año 3, No 1: pp. 97-118. 
IVORRA, María Jesús (1997): El recurso de casación para la unificación de doctrina (Valencia, Tirant lo Blanch) 103 pp.

LÓPEZ, Julián (2006): "Debido proceso en Chile: Hacia un principio generador de reglas", BORDALÍ, Andrés (coord.), Justicia constitucional y derechos fundamentales (Santiago, Universidad Austral de Chile, LexisNexis) pp. 181-207.

Morelli, Mario (2001): "Rapporti tra Corte di cassazione e Corte costituzionale nell' interpretazione della norma giuridica e nell' applicazione del precetto costituzionale", AA.VV., Le corti supreme. Atti del convengo di Perugia, 5-6 maggio 2000 (Milán, Giuffrè), pp. 81-92.

PÉREZ GORDO, Alfonso (1983): El tribunal constitucional y sus funciones (Barcelona, Bosch) 190 pp.

RodrígueZ-PIÑERO, Miguel (1999): El recurso de casación para la unificación de doctrina: Revisión crítica (Madrid, La ley) 315 pp.

Romero Seguel, Alejandro (2004): La jurisprudencia de los tribunales como fuente del Derecho. Una perspectiva procesal (Santiago, Editorial Jurídica de Chile) 149 pp.

Rousseau, Dominique (2004): "Faut-il supprimer le Conseil Constitutionnel?", Rousseau, Dominique (editor), Le Conseil Constitutionnel en questions (París, L'Harmattan) pp. 7-26.

Rubio Llorente, Francisco (1995): “El recurso de amparo constitucional”, en: AA.VV., La jurisdicción constitucional en España. La Ley Orgánica del Tribunal Constitucional: 1979 -1994 (Madrid, Centro de Estudios Constitucionales) pp. 125-173.

Silvestri, Elisabetta (2001): "Corti supreme europee: Accesso, filtri e soluzione", AA.VV., Le corti supreme. Atti del convengo di Perugia, 5-6 maggio 2000 (Milán, Giuffrè) pp. 105-116.

SILVESTRI, Gaetano (2001): "Le corti supreme negli ordinamenti costituzionali contemporanei”, AA.VV., Le corti supreme. Atti del convengo di Perugia, 5-6 maggio 2000 (Milán, Giuffrè) pp. 35-49.

TARUfFo, Michele (1991): Il vertice ambiguo. Saggi sulla cassazione civile, (Bolonia, Il Mulino) $189 \mathrm{pp}$.

TARUfFo, Michele (2001): "Le corti supreme europee: Accesso, filtri e soluzione", AA.VV., Le corti supreme. Atti del convengo di Perugia, 5-6 maggio 2000 (Milán, Giuffrè) pp. 95-104.

VIALA, Alexandre (1999): Les réserves d'interprétation dans la jurisprudente du Conseil Constitutionnel (París, Bibliothéque constitutionnelle et de science politique, LGDJ) 313 pp.

\section{JURISPRUDENCIA CITADA}

Sentencia sobre ley que crea juzgados laborales y juzgados de cobranza laboral y provisional (2005): Tribunal Constitucional, 11 de mayo de 2005. 